\title{
INFLUENCE OF TOOL ROTATIONAL SPEED AND AXIAL LOAD IN FRICTION STIR WELDING (FSW) OF HIGH STRENGTH ALUMINUM
} ALLOYS

\author{
M. S. Mahany ${ }^{1}$, Reham Reda Abbas', M. M. Z. Ahmed ${ }^{3}$, Hoda Abdelkader ${ }^{4}$ \\ ${ }^{l}$ M.S.Mahany, Mechanical Department, Faculty of Engineering-Helwan, Helwan University, Cairo, Egypt \\ ${ }^{2}$ Reham Reda, Mechanical Department, Faculty of Engineering-Helwan, Helwan University, Cairo, Egypt \\ ${ }^{3}$ M. M. Z. Ahmed, Metallurgical and engineering material Department Faculty of Petroleum and Mining Engineering, \\ Suez Canal University, Suez, Egypt \\ ${ }^{4}$ Hoda Abdelkader, Mechanical Department, Faculty of Engineering-Helwan, Helwan University, Cairo, Egypt
}

\begin{abstract}
The aim of the present work was to study the effect of tool rotating speed, and axial load on microstructure, tensile properties, and hardness distribution of FSW butt joints of AA2024-T3 and AA7075-T6 Al-alloys. The joints consists of two plates of different thickness (4 and 5mm). Threaded conical pin and concave surface tool shoulder was manufactured from tool steel H13. Specially designed FSW machine was used to weld the joints. AA2024-T3 was put at the advancing side (AS), while AA7075-T6 was set at the retreating side $(R S)$. Tool axis was tilted by angle $3^{\circ}$ without offset. Single FSW pass was applied to produce the joints. FSW process was performed at steady feed rate $50 \mathrm{~mm} / \mathrm{min}$. Rotational speed ranges between 400 and 1600 rpm, and axial force ranges between 1000 and $1450 \mathrm{Kg}$ were used in the present study. Constant plunging rate and dwell time of $3 \mathrm{~mm} / \mathrm{min}$, and 15 second respectively, were used for all conditions. Microstructure changes indicated that stir zone size increased gradually with excess tool rotary speed, and axial load. Increasing of both tool rotary speed, and axial load resulted in increasing the average value of grain size in stir zone, which was attributed to high amount of heat generation between the tool and workpiece. Mechanical investigation indicated that the maximum tensile strength about 378.6 Mpa was achieved at 1200 rpm, and axial load $1300 \mathrm{Kg}$. Hardness increased in SZ proportionally with tool rotary speed, and axial load due to the better mixing structure, whereas it reached the minimum value at heat affected zone (HAZ) of AA2024-T3 Al-alloy due to the grain growth caused by temperature raising.
\end{abstract}

Keywords: Friction Stir Welding (FSW), AA2024-T3, AA7075-T6, Rotational Speed, Axial Load, High Strength Al-Alloys

\section{INTRODUCTION}

High strength Al- alloys especially 2xxx, and 7xxx series are classified as one of the most important materials in industry. These Al-alloys are used in many critical industries such as automotive, rail, aircraft, aerospace, and shipbuilding industries. Joining of such Al-alloys face some barriers when using fusion welding techniques. Fusion welding techniques raise the welding temperature above the melting point of the base metals, which cause formation of solidification and liquation cracks, and then poor mechanical properties obtained [1]. These cracks mainly made joining operation of these Al-alloys is impossible using fusion welding techniques, and so they classified as non weldable by fusion welding. It was reported failed try for joining AA2024-T3 and AA7075-T6 Al-alloys by Gas tungsten Arc welding (GTAW) [2]. A solid state technique, was developed in 1991, basically for welding these Alalloys which is called Friction stir welding (FSW). In FSW process a tool with especial design (material and geometry) rotates with a predetermined rotational velocity. This tool is plunging into workpieces and frictional heat generate due to the relative motion between the tool and workpieces. The temperature of the welding region being lower than the melting temperature of the workpieces material, so most issues related to fusion welding is avoid. Frictional heat with tool rotation cause high plastic deformation to the material in the welding zone, resulting in recrystallization of the material in this region. FSW tool is moving parallel to the contact line between the workpieces for extend the stirring action along the joining length [3]. Joining of AA2024-T3 with AA7075-T6 Al-alloys using FSW process was achieved great results but the barrier is how to determine the best process parameters which leading to sound joints with good mechanical features. This paper interested in studying influence of FSW machine variables such as tool rotary speed, and axial force on microstructure form, and mechanical behaviors of the FS welded joints.

Saad Khodir et al[4] discussed the changes in microstructure, tensile properties, and hardness distribution of friction stir welded joints, at different values of rotary speed with replacement of the location of plates. Macrostructure investigation revealed mixed structure and onion ring pattern was formed with increasing rotational speed. Hardness increased with increasing rotational speed in the SZ. Maximum tensile strength of the joints of 423 
MPa was achieved at $1200 \mathrm{rpm}$ when 2024-T3 Al alloy located on the advancing side (AS).

Avinash, et al[5] studied the ability of FSW technique to make defects free dissimilar joints made of AA2024-T3 with AA7075-T6 Al-alloy. Joints were welded using different values of rotary and transverse speeds. No macroscopic defects have been observed in the welded joints. The higher ultimate tensile strength values have been produced at rotational speed of $1400 \mathrm{rpm}$ and lower welding speed of $80 \mathrm{~mm} / \mathrm{min}$.

Dubourg et al[6] FSW process variables including tool rotary speed, and welding speeds have been studied to detect their effect on weld quality. Metallurgical structure investigation, and tensile test were performed for lap joints of AA7075-T6 stringers and AA2024-T3 skin. Hooking defect can be avoided through double pass welds with overlapping the advancing sides, also top plate thinning defect can be eliminated by changing of rotation speed direction. The best quality welded joint is achieved at rotation speed of $700 \mathrm{rpm}$, and welding speed of $700 \mathrm{~mm} /$ $\min$

A.A.M. da Silva, et al[7] studied the effect of tool rotary speed, and axial force effect on mechanical features of welded joints of AA2024-T3 with AA7075-T6 by FSW technique. Yield strength value was very small for the welded joints compared to the base metal.Tensile test for $1000 \mathrm{rpm}$ FSW condition show that the ultimate tensile and yield strength have been reached $443 \mathrm{MPa}$ and $229 \mathrm{MPa}$ with $7.6 \%$ elongation.

Therefore another research was performed to analyze the impact of FSW process machine variables like the tool rotary speed value and axial force on quality, welding characteristics of dissimilar joints of AA 2024-T3 and AA7075-T6 Al-alloys. Generally the state of friction stir welded joint depends on many variables like tool rotary speed, feed rate, tool design, workpieces thickness, workpieces location, and joint type, etc.

The aim of this work was to study the influence of axial force, and tool rotary speed on microstructure, tensile properties, and hardness distribution of FSW dissimilar butt joints of AA7075-T6 and AA2024-T3 Al-alloys. In particular relationship between heat input and average value of grain size in nugget zone (NZ) had been performed.

\section{EXPERIMENTAL PROCEDURES}

\subsection{Material}

Two sheets of 2024-T3 and 7075- T6 Al-alloys were obtained to carry out the experimental program. The chemical composition of the two alloys, listed in Table 1, was checked using X-ray fluorescence (XRF) portable analyzer.

The sheets were cut into plates of dimensions $200 \times 100 \times 4 \mathrm{~mm}$ forAA2024-T3 and $200 \times 100 \times 5 \mathrm{~mm}$ for
AA7075-T6 Al-alloys. Mechanical properties of the base alloys displayed in Table 2.

\subsection{FSW Tool}

FSW tool was made from tool steel H13. The tool pin was designed as threaded conical pin with $6 \mathrm{~mm}$ major diameter, $4 \mathrm{~mm}$ minor diameter, as well as $3.7 \mathrm{~mm}$ height. Tool shoulder surface was chosen to be concave with $20 \mathrm{~mm}$ diameter. Figure 1 shows FSW tool profile used in this study.

\subsection{FSW Process}

The mating surface between the two plates to be welded was prepared using emery papers to ensure that there were no oxides or impurities before clamping for welding.

AA2024-T3 Al-alloy was installed in the advancing side (AS), whereas AA7075-T6 was set at the retreating side (RS). Tool axis was tilted by angle $3^{o}$ without offset. Setup of FSW operation including clamping of the two workpieces, tool installation, and the FSW operation is shown in Fig. 2. Single FSW pass was applied to produce the joints using specially designed FSW machine.

FSW process was performed at steady feed rate $50 \mathrm{~mm} / \mathrm{min}$, different values of rotary speed (400-1600 rpm), and axial force $(1000-1450 \mathrm{Kg})$. FSW tool was plunged at constant rate $3 \mathrm{~mm} / \mathrm{min}$, followed by 15 second as dwell time for all conditions. FSW conditions used in each experiment are listed in Table 3.

Table -1:Al-alloys Chemical Composition

\begin{tabular}{|l|l|l|l|l|l|l|l|l|}
\hline \multirow{2}{*}{ Materials } & \multicolumn{2}{|l}{ Chemical Composition (wt. \%) } \\
\cline { 2 - 9 } & $\mathrm{Cu}$ & $\mathrm{Mg}$ & $\mathrm{Fe}$ & $\mathrm{Cr}$ & $\mathrm{Zn}$ & $\mathrm{Ti}$ & $\mathrm{Si}$ & $\mathrm{Al}$ \\
\hline $\begin{array}{l}\text { AA2024- } \\
\text { T3 }\end{array}$ & 3.24 & 1.36 & 0.25 & 0.09 & 0.02 & 0.14 & 0.63 & 94.2 \\
\hline $\begin{array}{l}\text { AA7075- } \\
\text { T6 }\end{array}$ & 1.83 & 2.04 & 0.17 & 0.247 & 6.59 & 0.16 & 0.15 & 88.8 \\
\hline
\end{tabular}

Table -2: Al-alloysMechanical Properties

\begin{tabular}{|l|l|l|}
\hline Property & AA2024-T3 & AA7075-T6 \\
\hline Ultimate Tensile stress (MPa) & 446 & 577 \\
\hline Tensile Yield stress (MPa) & 315 & 520 \\
\hline Elongation (\%) & 22 & 15.5 \\
\hline Microhardness (HV) & 137 & 176 \\
\hline
\end{tabular}

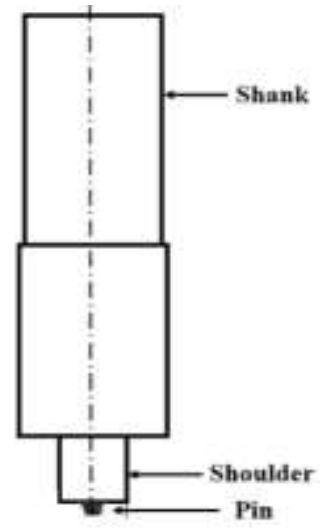

Fig -1: FSW tool profile 
Table -3: FSW conditions

\begin{tabular}{|c|c|c|c|}
\hline Exp. & $\begin{array}{l}\text { Feed rate V } \\
(\mathrm{mm} / \mathrm{min})\end{array}$ & $\begin{array}{l}\text { Rotation } \\
\text { speed } \\
(\mathrm{rpm})\end{array}$ & $\begin{array}{l}\text { Axial load } \\
\mathrm{F}(\mathrm{kg})\end{array}$ \\
\hline 1 & \multirow{4}{*}{50} & \multirow{4}{*}{$\begin{array}{l}400 \\
800 \\
1200 \\
1600\end{array}$} & \multirow{4}{*}{$\begin{array}{l}1000 \\
1150 \\
1300 \\
1400\end{array}$} \\
\hline 2 & & & \\
\hline 3 & & & \\
\hline 4 & & & \\
\hline
\end{tabular}

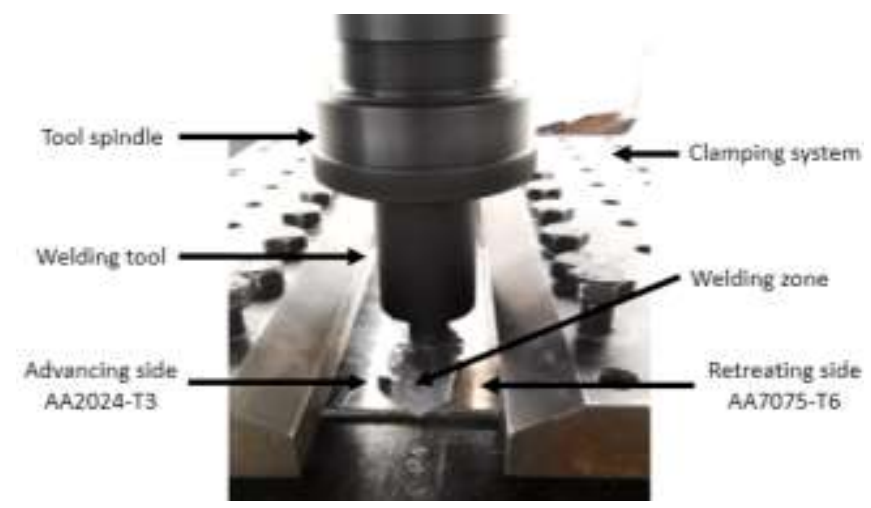

Fig -2: FSW process

\subsection{Microstructural Examination}

Microstructure investigation of the FSW joints was carried out on a cross-section perpendicular to the welding line using Axiotech optical microscopy. Samples were prepared using emery papers, followed by polishing using alumina and a colloidal silica suspension. Specimens were etched by standard Keller's chemical reagent $(95 \mathrm{~mL} \mathrm{H} 2 \mathrm{O}, 2.5 \mathrm{ml}$ HNO3, $1.5 \mathrm{~mL} \mathrm{HCl}$, and $1 \mathrm{ml} \mathrm{HF}$ ).

\subsection{Tensile Test}

Tensile test was measured after thirty days of natural aging. Electro mechanical Universal Testing Machine (UTM) of $100 \mathrm{KN}$ load was used for applying the test. Three tensile specimens were taken from each joint, along the normal direction of the weld. The tensile specimens were machined according to ASTM E8M-09[8]. Tensile properties, including ultimate strength, yield and elongation\% of each joint were evaluated.The location of each sample in the welded plates displayed in Fig. 3 .

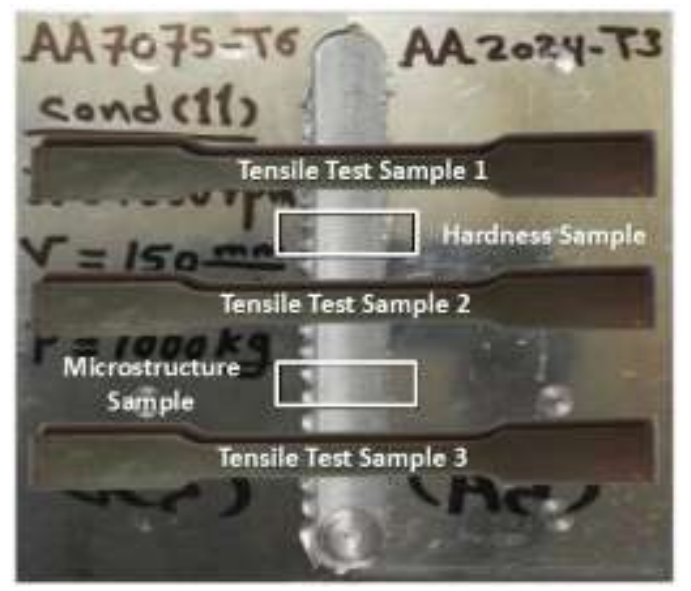

Fig -3: Position of Specimens for each welded joint.

\subsection{Microhardness Test}

Microhardness profiles of the FSW joints were measured after thirty days of natural aging. Hardness was measured along a mid-line of the weld area, perpendicular to the weld direction, with $1 \mathrm{~mm}$ interval. Microhardness test was performed on polished surface, under load of 100 grams and constant holding time of about 15 seconds. Vickers microhardness testing machine with applied force varied from 15 to 2000 gram.

\section{RESULTS AND DISCUSSION}

\subsection{Macrostructure Evaluation}

Figure 4 shows the macrostructure analysis of dissimilar joints produced at different welding conditions ( reported in Table s).AA2024-T3 alloy was set on the advancing side. As clearly observed no defects were detected and all joints have a good welding penetration.Welding zone has a typical elliptical shape, which is wider at the top.This may be due to the exerted axial load through tool shoulder.Size of weld zone was partially narrow without clear mixing pattern at low rotational speed of $400 \mathrm{rpm}$. Increasing rotational speed and axial load to $1600 \mathrm{rpm}$, and $1450 \mathrm{Kg}$ respectively; led to large size of welding zone with irregular shape of mixing (Fig. 4). Higher rotational speed caused excessive plastic deformation, high heat input, and then turbulent material flow in the welding zone.These results are in agreement with the reported in literature for similar material [4].Onion ring patterns were observed and are clear at rotational speed value of 800 and $1200 \mathrm{rpm}$ respectively. These bands indicate that good mixing and stirring action between the two base metals in the welding region were occurred.

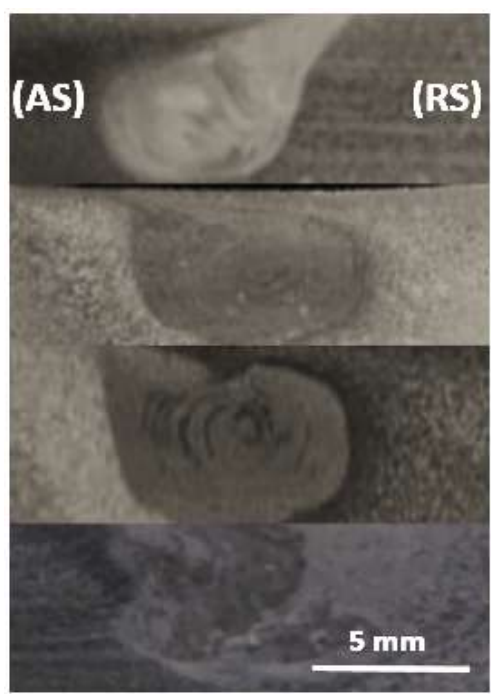

Fig -4: Macrostructures of welds ateach condition (400 rpm$1000 \mathrm{~kg}),(800 \mathrm{rpm}-1150 \mathrm{~kg}),(1200 \mathrm{rpm}-1300 \mathrm{~kg}),(1600 \mathrm{rpm}-$ $1450 \mathrm{~kg}$ ) respectively

\subsection{Microstructure}

The microstructure of the base metals is shown in Fig. 5 (a), and (b) respectively. It can be shown that, the direction of rolling is clearly observed. The grains are elongated along the direction of rolling with a stray distribution of 
precipitates. Microstructures of various zones in each joint displayed in Fig. 6 respectively. Different zones appeared in the welded region such as stir zone (SZ) or nugget zone (NZ), thermo-mechanical affected zone (TMAZ), and heat affected zone (HAZ). Nugget zone exposed to excessive plastic deformation and high temperature due to pin rotation and axial pressure with high generation of frictional heat during FSW process. Large plastic deformation and temperature lead to dynamic recrystallization refinement process of grains in nugget zone. Grains in nugget zone seem very equiaxed fine grains compared to the base metals (BM) as appear for all experiments. This dynamic recrystallization process was also reported [10]. Microstructure of stir zone composed of lamellar structure with grey and partially glum grey chains with different disparity and grain size. The degree of disparity in size of nugget zone grains was indicated at the same welding conditions certainly with high magnifications. This disparity due to the nonlinear temperature distribution across the weld region, which indicates to the significant role of FSW process variables, as tool rotary speed and axial force. Thermo-Mechanically Affected Zone (TMAZ) is highly deformed zone surrounds the stir zone. TMAZ was consisted of high deformed non-recrystallized grains. TMAZ is subjected to plastic strains and frictional heating, but is not enough to activate the mechanisms responsible for recrystallization. The grains in TMAZ was observed as bended or deflected due to the tool rotation, which indicating the large plastic deformation in this region. Heat Affected Zone (HAZ) is the third region which exposed to thermal cycle due to the generated frictional heating without any plastic deformation. Temperature in stir zone result in softening grains in this region occurred. Generally HAZ is commonly described as the weakest zone in the weld obtained by FSW, due to coarse grain structure compared to other regions.

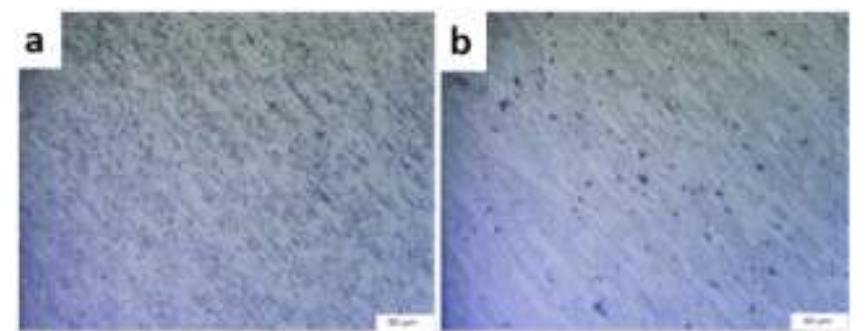

Fig -5: Microstructures of the Base Metals a) AA2024-T3 b) AA7075-T6.

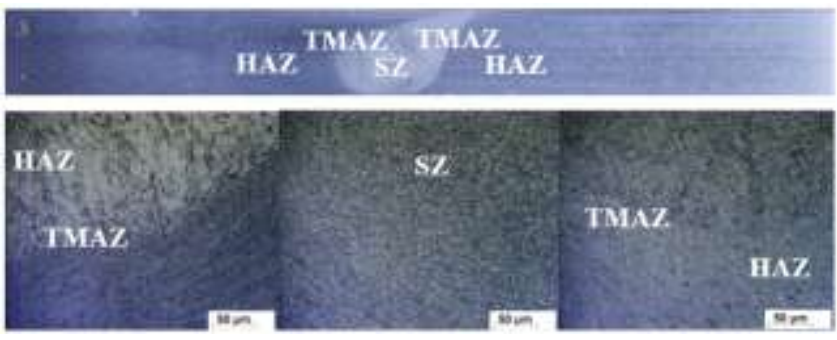

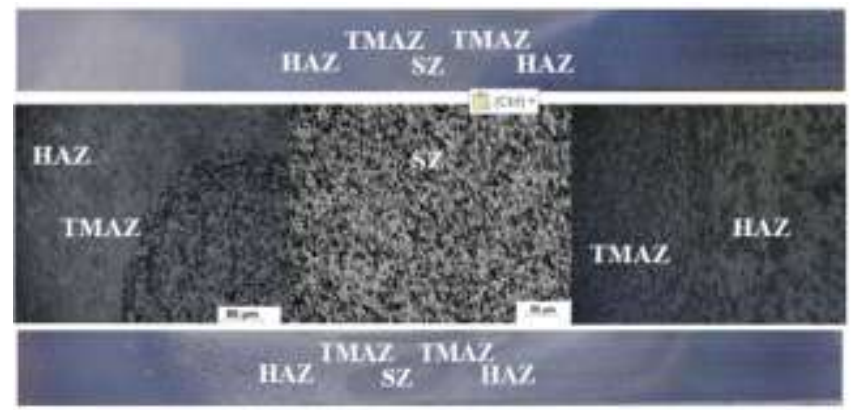
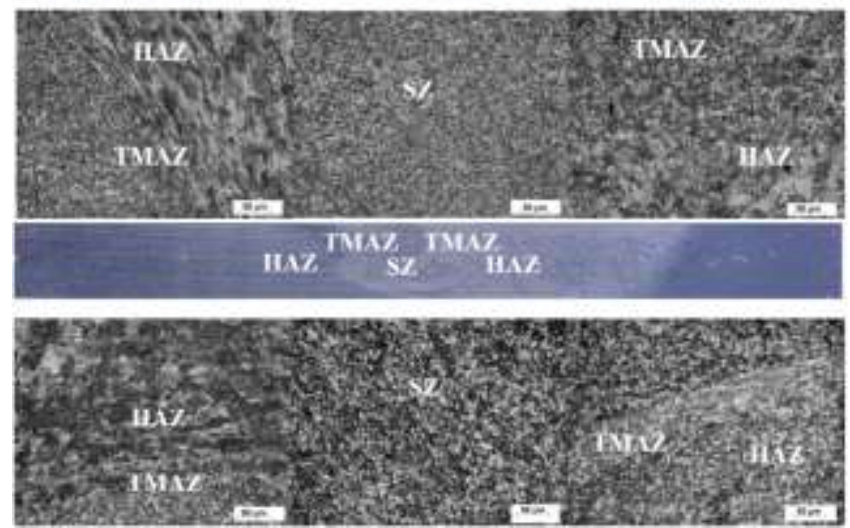

Fig -6: Microstructures of different zonesin the welded region stir zone, thermomechanically affected zone, and heat affected zone.

\subsection{Heat input}

By neglecting convective heat transfer a typical approach forheat generation was introduced byFrigaard et al[11] for prediction heat input valueinFSW process using the expression:

$$
\mathrm{Q}=\frac{2 \pi}{3 \mathrm{~V}} \mu \mathrm{FNR}_{\mathrm{s}} \boldsymbol{\eta}(1)
$$

Where, Q: is the heat input during FSW process in J.mm-1, $\mathrm{V}$ is the feed rate in $\mathrm{mm} / \mathrm{s}, \mu$ : is the coefficient of friction between tool and workpieces assumed $\mu=1, F$ is the axial load in $\mathrm{KN}, \mathrm{N}$ is the tool rotary speed in rps, Rsis the shoulder radius in $\mathrm{m}$, and $\eta$ is the process efficiency assumed as 0.8 .

The heat input values for each condition are listed in Table 4.

Table -4:Heat Input values in each condition

\begin{tabular}{|c|c|c|c|c|}
\hline Co. & $\begin{array}{l}\mathrm{V} \\
(\mathrm{mm} / \mathrm{min})\end{array}$ & $\begin{array}{l}\mathrm{N} \\
(\mathrm{rpm})\end{array}$ & $\begin{array}{l}\mathrm{F} \\
(\mathrm{Kg})\end{array}$ & $\begin{array}{l}\mathrm{Q} \\
\text { (KJ.mm-1) }\end{array}$ \\
\hline $\mathrm{C} 1$ & \multirow{4}{*}{50} & 400 & 1000 & 1.315 \\
\hline $\mathrm{C} 2$ & & 800 & 1150 & 3.024 \\
\hline $\mathrm{C} 3$ & & 1200 & 1300 & 5.128 \\
\hline $\mathrm{C} 4$ & & 1600 & 1450 & 7.627 \\
\hline
\end{tabular}

The heat input values depends mainly on the rotational tool speed and axial force, while the other parameters are constant throughout the present work. Thus, the heat input value is proportional to the rotational speed and applied axial load respectively. 


\subsection{Average Grain Size Measurement}

Different size was observed for the grains in stir zone. Numerical calculation was applied to determine the average value of grains size using Image $\mathbf{J}$ software. It was clear that grain size depended on both rotational speed, and axial load, whereit increases with increasing tool rotary speed, and axial force due to increasing heat input. Figure7represented the change of grain size with rotation and axial forceinside the stir zone. Figure 8 shows the relationshipbetween the average measured grain size, in the SZ, and the heat input. It is clearly observed that, the average grain size increases with increasing heat input to 7.627 (KJ.mm-1). This result indicates that the increase in grain size is a direct result to the increase in heat input which is proportional to the tool rotational speed and applied axial force

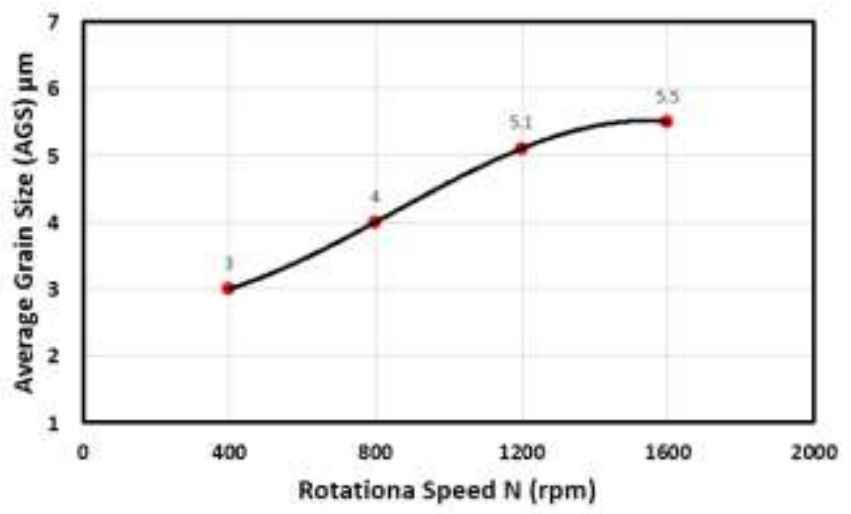

Fig -7: Relation between rotational speed, axial load, and the resulted average grain size in SZ.

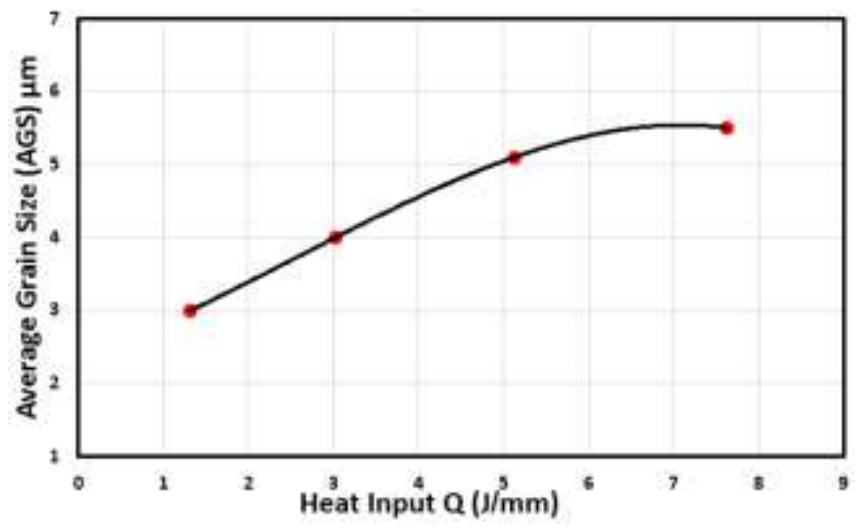

Fig -8: Relation between heat input, and grain size in SZ

\subsection{Tensile Properties}

Transverse tension test wasdone using electro-mechanical controlled Universal Testing Machine. Ultimate tensile strength, $0.2 \%$ offset yield strength, percentage of elongation had been determined for all conditions. Disparity of strength values attributed to many reasons such as the generated frictional heat, plastic deformation, and material flow pattern, which in turn depend on process variables. Tool rotary speed, and axial load effect on tensile testresults displayed in the following section.

\subsubsection{Ultimate Tensile Strength}

The ultimate tensile strength $\left(\boldsymbol{\sigma}_{\text {U.T.S }}\right)$ of all welded joints is found to be lower than the strength of the base metals. At low tool rotational speed, and axial load especially at 400 $\mathrm{rpm}$ and $1000 \mathrm{Kg}$, the heat generation is not sufficient to soften the material and therefore results in inefficient mixing of the materials. Hence jointsstrength are found to be low. Ultimate tensile strength decreased with increasing rotational speed, and axial load to $800 \mathrm{rpm}-1150 \mathrm{Kg}$, this may attributed to low pressure at high rotational speed which leading to excessive metal splash out from stirring zone. Increasing rotational speed, and axial load up to 1200 rpm-1300 Kgresulting in increasing strength to the maximum value which was about $380 \mathrm{MPa}$.

More increasing in rotational speed, and axial load to 1600 rpm- $1450 \mathrm{Kg}$ caused marked reduction in the value of tensile strength due to excessive increase in heat generation which can be attributed to increase in grain size. This high heat generation make excessive plastic deformation in stirring zone, and poor material flow resulting informing of some defects like tunnel, and kissing bond defects. Elangovan reported similar results in their work during FSW of AA2219 Al-alloy[12]. Strength distribution at each condition displayed in Fig. 9.

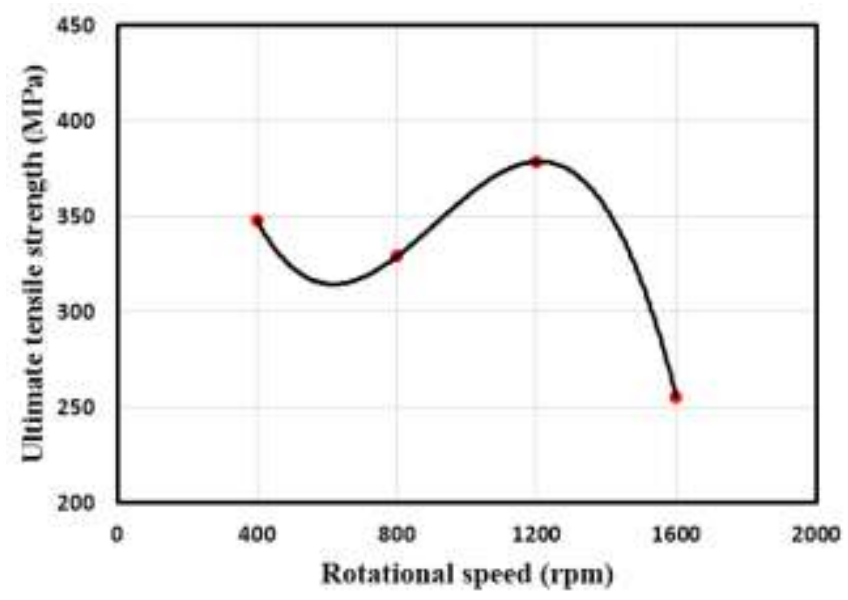

Fig -9: Relation between rotational speed, axial load, and ultimatetensile strength.

\subsubsection{Yield Strength}

Yield strength follow the same trend of tensile strength, and slightlyincreased with increasing tool rotary speed, and axial load.Maximum yields stress of 281.2 MPa achieved at 1200 rpm and $1300 \mathrm{Kg}$, while the minimum value $219 \mathrm{MPa}$ is at $1600 \mathrm{rpm}$. Tool rotary speed, and axial loadeffect on the yield strength is shown in Fig. 10. 


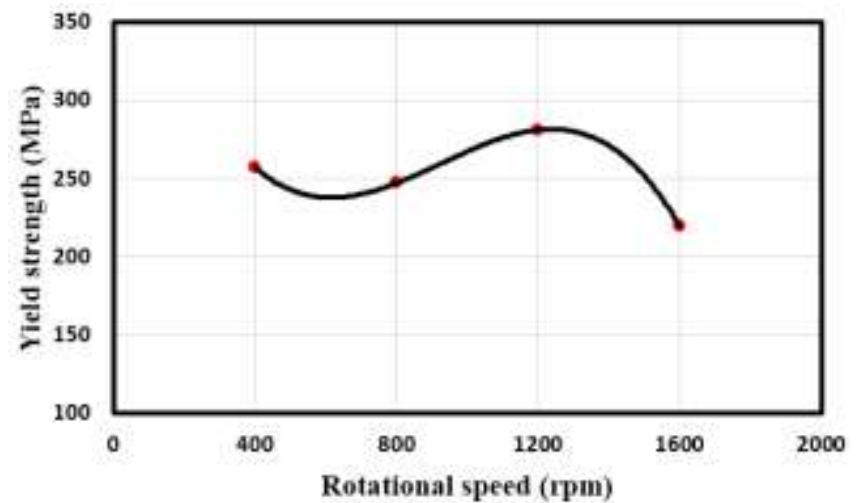

Fig -10: Relation between rotational speed, axial load, and yield strength.

\subsubsection{Percent of Elongation \%}

Results indicated that there was a significant influence of FSW process variables on \% elongation of each joint. Elongation increased with increasing rotational speed up to $1200 \mathrm{rpm}-1300 \mathrm{Kg}$, and then it decreased with increasing rotational speed, and axial load to $1600 \mathrm{rpm}-1450 \mathrm{Kg}$, due to high temperature grain growth which more means increase in size of grains hence more elongation. Condition of $1200 \mathrm{rpm}-1300 \mathrm{Kg}$ achieved the maximum elongation value of $9.2 \%$, while the minimum value $3 \%$ was at 1600 $\mathrm{rpm}$. The percent of elongation for each joint is shown in Fig. 11.

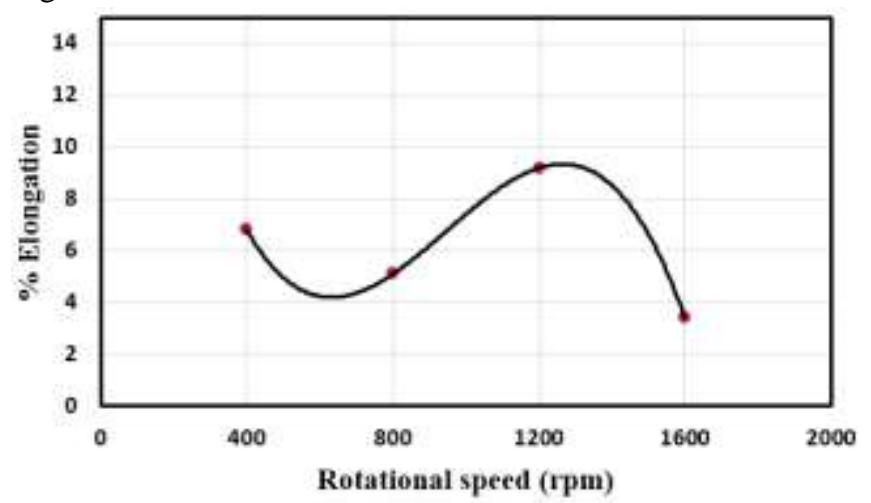

Fig -11: Relation between rotational speed, axial load, and percent of elongation

\subsection{Hardness Distribution}

Microhardness distribution profiles of joints after thirty days of natural aging represented inFig. 12. Hardness test was done across the transverse section of the welds. Obvious change in hardness distribution appear in nugget zone.Increasing of rotational speed, and axial load led to increasing the hardness value in stirring zone due to the mixing between the two plates in it. Hardness decreased in heat affected zone (HAZ) at both sides. The minimum value of hardness 112 Hvwas obvious and noticedat(HAZ) of 2024-T3 Al-alloy side due to coarse grains structure.

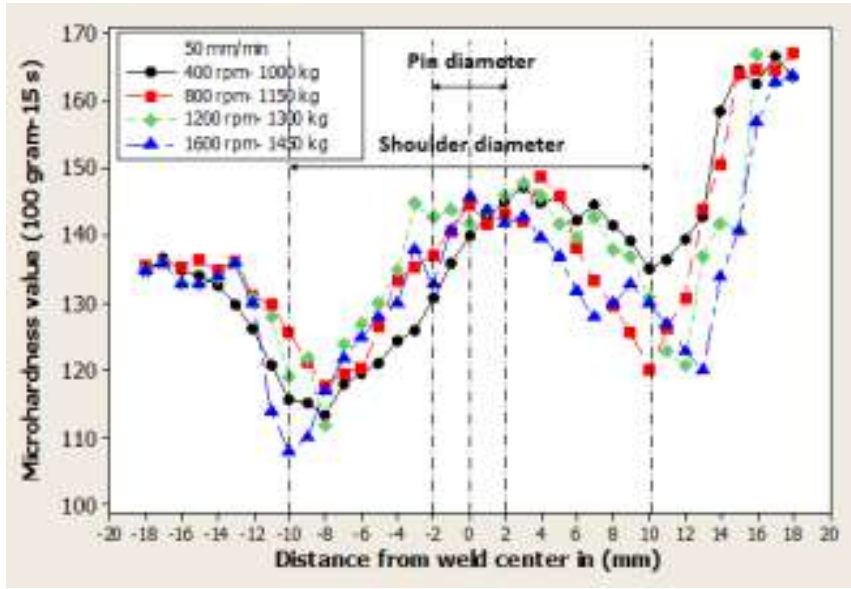

Fig -12: Hardness distribution along the mid line of the welded joints

\section{CONCLUSION}

Two high strength Al-alloys with different thickness had been welded using FSW technique in butt joint order. Machine variables effects like toolrotary speed, and axial loadon microstructures, tensile properties, hardness distributions, and stir zonegrain size were studied. The results of this study summarizedin the following points;

- FSW process is very successful technique for joining high strength dissimilar Al-alloys, and get sound joints when different thickness used.

- Size of stir zone was relatively small, and there was no clear mixing in form of onion rings between Al-alloys at toolrotary speed of $400 \mathrm{rpm}$, and axial load of $1000 \mathrm{Kg}$

- Increase of tool rotary speed, and axial load led to generated the mixed structure in a form of onion ring pattern was formed which has equiaxed grains in SZ. The size of stirring zone became larger and the mixing structure was clear.

- Mean value of grain size in the stirring zone increased with at hightool rotary speed, and axial force, due to high frictional heat generated.

- The maximum hardness in the SZ was obtained at 1200 rpm of rotation speed, and $1300 \mathrm{Kg}$ of axial load. High hardness value in SZ indicates good mixing structure.

- Hardness reach its minimum value at HAZ of AA2024T3. The minimum value of hardness observed in HAZ of2024-T3 Al-alloy at all conditions and its values slightly reduced with increasing rotary speed, and axial load.

- Tensile strength increased by increasing both rotary speed and axial load up to $1200 \mathrm{rpm}$, and $1300 \mathrm{Kgto}$ reach maximum value about $378.7 \mathrm{MPa}$, then it reduced suddenly with increasing rotational speed, and axial load to $1600 \mathrm{rpm}$, and $1450 \mathrm{Kg}$ due to excessive heat input and the presence of tunnel defect in SZ, in addition to kissing bond defect in SZ-TMAZ interface.

- A particular combination of FSW process variables must be adjusting to get defects free joints. Tool rotary speed save local frictional heat and proper stirring action. Axial force responsible for preventing stirring material from flow out the welding zone in form of metal splash. 


\section{ACKNOWLEDGEMENT}

Firstly, I would like to express my deep and sincere gratitude to my research supervisors, Prof. Dr. Hoda AbdElkader Abd-Elhalim, Prof. Dr. Mohamed Mohamed Zaky, and Dr. Reham Reda Abbas for their great support, motivation, immense knowledge, encouragement, and most importantly patience. Their guidance is a large part in making this research possible.

\section{REFERENCES}

[1] R. N. Deekhunthod, "Weld Quality in Aluminium Alloys," 2014.

[2] R. S. Mishra, "Preface to the Viewpoint Set on friction stir processing," ScriptaMaterialia, vol. 58, pp. 325-326, 2008.

[3] P. Bahemmat, M. Haghpanahi, M. K. B. Givi, and K. R.Seighalani, "Study on dissimilar friction stir butt welding of AA7075-O and AA2024-T4 considering the manufacturing limitation," The International Journal of Advanced Manufacturing Technology, vol. 59, pp. 939-953, 2012.

[4] S. A. Khodir and T. Shibayanagi, "Microstructure and mechanical properties of friction stir welded dissimilar aluminum joints of AA2024-T3 and AA7075-T6," Materials transactions, vol. 48, pp. 1928-1937, 2007

[5] P. Avinash, M. Manikandan, N. Arivazhagan, K. D. Ramkumar, and S. Narayanan, "Friction stir welded butt joints of AA2024 T3 and AA7075 T6 aluminum alloys," Procedia Engineering, vol. 75, pp. 98-102, 2014

[6] L. Dubourg, A. Merati, and M. Jahazi, "Process optimisation and mechanical properties of friction stir lap welds of 7075-T6 stringers on 2024-T3 skin," Materials \& Design, vol. 31, pp. 3324-3330, 2010

[7] Da Silva, E. Arruti, G. Janeiro, E. Aldanondo, P. Alvarez, and A. Echeverria, "Material flow and mechanical behaviour of dissimilar AA2024-T3 and AA7075-T6 aluminium alloys friction stir welds," Materials \& Design, vol. 32, pp. 2021-2027, 2011

[8] E. ASTM, "Standard test methods for tension testing of metallic materials," Annual book of ASTM standards. ASTM, 2001

[9] Y. S. Sato, M. Urata, and H. Kokawa, "Parameters controlling microstructure and hardness during friction-stir welding of precipitation-hardenable aluminum alloy 6063," Metallurgical and Materials Transactions A, vol. 33, pp. 625-635, 2002

[10] P. B. Srinivasan, K. Arora, W. Dietzel, S. Pandey, and M. Schaper, "Characterisation of microstructure, mechanical properties and corrosion behaviour of an AA2219 friction stir weldment," Journal of Alloys and Compounds, vol. 492, pp. 631-637, 2010

[11] Ø. Frigaard, Ø. Grong, and O. Midling, "A process model for friction stir welding of age hardening aluminum alloys," Metallurgical and materials transactions A, vol. 32, pp. 1189-1200, 2001
[12] K. Elangovan and V. Balasubramanian, "Influences of tool pin profile and tool shoulder diameter on the formation of friction stir processing zone in AA2219 aluminium alloy," Materials \& design, vol. 29, pp. $362-373,200$

\section{BIOGRAPHIES}

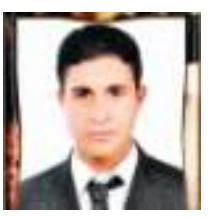

M. S. Mahany: Demonstrator at Faculty of Engineering-Helwan, Mechanical Department, Production Engineering Division, Helwan University, Cairo, Egypt

Reham Reda Abba: Lecturer at Faculty of EngineeringHelwan, Mechanical Department,Production Engineering Division, Helwan University, Cairo, Egypt

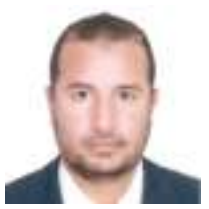

M. M. Z. Ahmed: Professor Assistant Metallurgical and engineering material Department Faculty of Petroleum and Mining Engineering, Suez Canal University, Suez, Egypt

Hoda Abdelkader:Professor at Faculty of EngineeringHelwan, Mechanical Department,Production Engineering Division, Helwan University, Cairo, Egypt 